\title{
Article
}

\section{Surface Activity of Humic Acid and Its Sub-fractions from For- est Soil}

\author{
Shijie Tian ${ }^{1}$, Weiqiang Tan ${ }^{1 *}$, Xinyuan Wang ${ }^{1}$, Tingting Li², Fanhao Song ${ }^{2}$, Nannan Huang ${ }^{2}$ \\ 1 School of Environmental and Municipal Engineering, Qingdao University of Technology, Qingdao 266033, \\ China; 2064983040@qq.com (S.T); 2219565207@qq.com (X.W) \\ 2 State Key Laboratory of Environmental Criteria and Risk Assessment, Chinese Research Academy of Envi- \\ ronmental Sciences, Beijing 100012, China; litingting193@163.com (T.L); sonfh@craes.org.cn (F.S); \\ nan625420052@163.com (N.H) \\ * Correspondence: tanweiqiang@qut.edu.cn
}

\begin{abstract}
Surface activity of humic acid (HA) and its six sub-fractions isolated from forest soil were characterized by surface tension measurements, dynamic light scattering, and laser doppler electrophoresis. The surface tension of HA and its sub-fractions reduced from $72.4 \mathrm{mN} \cdot \mathrm{m}-1$ to $36.8 \mathrm{mN} \cdot \mathrm{m}$ 1 in exponential model with the increasing concentration from 0 to $2000 \mathrm{mg} \cdot \mathrm{L}-1$. The critical micelle concentration (CMC) and Z-average particle size ranged from 216-1024 mg.L-1 and 108.2-186.9 nm for $\mathrm{HA}$ and its sub-fractions, respectively. The $\mathrm{CMC}$ have related with alkyl C, O-alkyl C, aromatic $\mathrm{C}$, and carbonyl $\mathrm{C}(\mathrm{p}<0.05)$, respectively, and could be predicted with the multiple linear regression

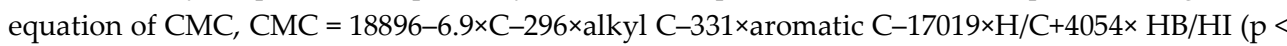
0.05). The maximum particle size was $5000 \mathrm{~nm}$ after filtered by a membrane with pore size of 450 $\mathrm{nm}$, indicating HA and its sub-fractions could progressed self-assembly at $\mathrm{pH} 6.86$. The aggregate sizes of number-base particle size distributions were mainly in six clusters including $2 \pm 1 \mathrm{~nm}, 5 \pm 2$ $\mathrm{nm}, 10 \pm 3 \mathrm{~nm}, 21 \pm 8 \mathrm{~nm}, 40 \pm 10 \mathrm{~nm}$, and $>50 \mathrm{~nm}$ analyzed by Gaussian model that maybe due to the inconsistency of the components and structures of the HA sub-fractions, requiring further study. It is significance to explore the surface activity of HA and its sub-fractions, which is helpful to clarify the environmental behavior of HA.
\end{abstract}

Keywords: Humic acid; Surface tension; CMC; Gaussian model

\section{Introduction}

Humic acid (HA) is a complex and heterogeneous mixture of aromatic and aliphatic organic compounds with organic supramolecular systems existing in waters, soils, and sediments [1-3]. Similar to synthetic surfactants, HA can form a micelle-like structure at high concentrations because of the amphiphilic properties with hydrocarbon chains as hydrophobic fractions, and carboxylic and nonionic polar portions as hydrophilic fractions [4-8]. Synthetic surfactants have many applications and high consumption rates in different fields including household cleaning detergents, personal care products, textiles and pesticide formulations, etc. [3, 9-11]. Previous researches documented that the engineered surfactants were toxic to microorganisms, plants (e.g., Sorghm bicolour, Helianthuus annuus, Phaseolus aureus, etc.), and aquatic organisms (e.g., D. magna, P. phosphorem etc ) [12-14]. As a natural surfactant, HA might have possible usage as an environment-friendly substitution of synthetic surfactants [15-18].

The concentration at which the micelle formation occurs is defined as the critical micelle concentration (CMC) that is an important parameter to describe a surfactant [5]. HAs showed a large range of $\mathrm{CMC}$ from several hundred to thousands. For example, the CMC was $7400 \mathrm{mg} \cdot \mathrm{L}^{-1}$ for commercial Aldrich HA [4], 800-3300 mg. $\mathrm{L}^{-1}$ of soil HA from southern Chile of uncultivated pasture areas of Collipulli, Andisols Ralun, Nueva Braunau, Fru- 
tillar, Osorno, Vilcun and Temuco [19]. 400-4040 $\mathrm{mg} \cdot \mathrm{L}^{-1}$ of HA derived from waste compost [5, 7], 289-777 $\mathrm{mg} \cdot \mathrm{L}^{-1}$ of soil HA sub-fractions from Nagano and Hyogo Prefecture, Japan [20]. The inconsistent CMC could be attributed to the complicated composition and structure of HAs, such as the hydrophobic group, the hydrophilic group, electrolyte, and temperature, etc. [21]. The separation of HA into sub-fractions was a powerful method to characterize the structure of humic substances, as well as to clarify the potential interaction mechanisms between HA and contaminants [1, 2, 22-24]. However, the sub-fractions of HA have not been widely used to investigate on surface activity of HA, including CMC and surface tension.

The multiple regression models were powerful method to model on the various research areas [25], including intention to obtain of mammogram [26], heating value of biomass fuels [27], and students' lessons scores [28] etc. Multiple regression equations were widely applied to investigate influence factors of CMC value, quantitively. For example, Liang, et al. [29] indicated the CMC have a significant linear correlation with alkyl C, and the sum content of $\mathrm{N}$ and $\mathrm{S}$ base on six samples of HAs derived from lignocelluloses waste, lignocelluloses plus food wastes, and Aldrich HA (Eq. S1) [17]. The significant linear relationships between $\mathrm{CMC}$ with alkyl $\mathrm{C}$ percentage and molecule weight (MW) were reported by Adani, et al. [30] with HA isolated from lignocelluloses waste, lignocelluloses plus food wastes, maize plant residue, as well as Aldrich HA (Eq. S2) [30]. The regression equation was also documented by Salati, et al. [3] according to 13 samples of HA from biomass such as urban green wastes, lignocelluloses waste, and green wastes, etc. (Eq. S3) [3]. The soil is the greatest source of HA, and the possible regression equations should be modified base on HA from soil because of the lack of data of HAs from the soil.

Dynamic light scattering (DLS) is applied to characterize the aggregation size of HAs base on Brownian motion of particles in an aqueous solution [31-33]. The average sizes of HAs, name as Z-average diameters ranging from 185-280 nm for Aldrich HA [32], from 210 to $280 \mathrm{~nm}$ for Elliott Soil HA ranged from International Humic Substances Society (IHSS) [34], and $185 \mathrm{~nm}$ for HA derived from Irish moss peat [35] base on DLS analysis. In addition, Z-average diameters are affected by many factors, such as cation concentration, $\mathrm{pH}$, salinity, etc. [36]. However, Z-average diameter could not reflect the truly polymodal character of HA, because its calculations assume the sample is monomodal. Gaussian distribution model is a common quantitative method in complex multicomponent systems, which can distinguish overlapped and hidden peaks in the spectral analysis including XPS, FTIR, ${ }^{13} \mathrm{C}$ NMR, etc. [37-39]. However, the Gaussian distribution model had not been utilized to analyze particle size distributions (PSD) of HA sub-fractions according to DLS analysis.

Therefore, six sub-fractions of Chinese standard HA from forest soil were applied to explore the relationship between properties of HAs with their surfactant activity. The objectives were 1) to determine the various surface activity for HA sub-fractions; 2) to modify and update the possible multiple linear regression equation of CMC with data of soil $\mathrm{HA}$, and 3) to visit the distribution characterization of hydrodynamic radii of HAs subfractions by Gaussian distribution model.

\section{Materials and Methods}

\subsection{Isolation and purification of $H A$ and its sub-fractions}

Chinese standard HA was isolated and purified from the surface soil of Jiufeng Mountain Forest, Beijing, China. The sample soil type is yellow earths. The carbon and nitrogen content of soil was $2.95 \%$ and $0.39 \%$, respectively. Briefly, the soil was sieved before through $2 \mathrm{~mm}$ mesh. Isolation and purification of HA were performed according to procedures recommended by the IHSS. Detailed information on the method has been previously reported [2]. The HA sub-fractions named as HA1-HA6 were isolated with $0.02 \mathrm{~mol} \cdot \mathrm{L}^{-1} \mathrm{Na}_{4} \mathrm{P}_{2} \mathrm{O}_{7}, 0.05 \mathrm{~mol} \cdot \mathrm{L}^{-1} \mathrm{Na}_{4} \mathrm{P}_{2} \mathrm{O}_{7}, 0.1 \mathrm{~mol} \cdot \mathrm{L}^{-1} \mathrm{Na}_{4} \mathrm{P}_{2} \mathrm{O}_{4}, 0.05 \mathrm{~mol} \cdot \mathrm{L}^{-1} \mathrm{NaOH}, 0.1$ $\mathrm{mol} \cdot \mathrm{L}^{-1} \mathrm{NaOH}$, and $0.25 \mathrm{~mol} \cdot \mathrm{L}^{-1} \mathrm{NaOH}$ in sequence with a solid to solution ratio of $1: 10$ (w: v) for $24 \mathrm{hrs}$. The Si and $\mathrm{Cl}^{-}$in the solution of HA sub-fractions were purified with 0.1 
$\mathrm{mol} \cdot \mathrm{L}^{-1} \mathrm{HCl}$ and $0.3 \mathrm{~mol} \cdot \mathrm{L}^{-1} \mathrm{HF}$, as well as dialysis membranes with $1 \mathrm{KD}$ (Spectra/Por6, Standard, RC, USA). All solutions were prepared in Milli-Q water (Millipore, USA), and all chemicals were AR grade unless mentioned otherwise. Detailed information on isolation and fractionation of humic substance are described elsewhere [1].

\subsection{Surface tension measurements}

The surface tension of HA and its sub-fractions were measured with the model Dataphysics DCAT21 (DataPhysics Instruments GmbH, Filderstadt, Germany.) with Wilhelmy method [40]. The Pt plate was cleaned by washing with $0.1 \mathrm{~mol} \cdot \mathrm{L}^{-1} \mathrm{HCl}$ solution and then Milli-Q water in sequence, and finally held in an alcoholic flame for more than $500^{\circ} \mathrm{C}$ for $1 \mathrm{~min}$. The stock solution for both $\mathrm{HA}$ and its sub-fractions was ca. $5000 \mathrm{mg} \cdot \mathrm{L}^{-1}$ at $\mathrm{pH} 6.86$ with $0.1 \mathrm{~mol} \cdot \mathrm{L}^{-1} \mathrm{~K}_{2} \mathrm{HPO}_{4} / \mathrm{KH}_{2} \mathrm{PO}_{4}$ as a buffer and $0.1 \mathrm{~mol} \cdot \mathrm{L}^{-1} \mathrm{NaCl}$ as background. The solutions for detecting were prepared by mixing the stock solutions with the appropriate volume of solution with both $0.1 \mathrm{~mol} \cdot \mathrm{L}^{-1} \mathrm{~K}_{2} \mathrm{HPO}_{4} / \mathrm{KH}_{2} \mathrm{PO}_{4}$ and $0.1 \mathrm{~mol} \cdot \mathrm{L}^{-1} \mathrm{NaCl}$. All solutions were filtered $0.45 \mu \mathrm{m}$ membrane and regulated at $25 \pm 0.5^{\circ} \mathrm{C}$ by a thermostat bath equipped with a circulator pump in the surface tension measurement experiment. The exponential model was surface tension vs. the concentration of HA sub-fractions were fitted with an exponential model (Eq. 1):

$$
\frac{\gamma}{\gamma_{0}}=\frac{\gamma_{\text {plateaus }}}{\gamma_{0}}+\frac{\Delta \gamma}{\gamma_{0}} \exp ^{-A c}
$$

Where $\gamma_{0}$ is the surface tension of aqueous solution at $\mathrm{c}=0, \gamma_{\text {plateaus }}$ is the value of the surface tension reduction curve plateaus, $\Delta \gamma$ is the maximum $\gamma$ variation that corresponding to the concentration (c), and $A$ is the reach of $\gamma_{\text {plateaus }}$ rate ( $\gamma$ per milligram).

The critical micellar concentration (CMC) of HA and its sub-fractions were calculated from the surface tension vs. log concentration plot. The CMC was established according to the interaction of the two lines describing premicellar and postmicellar regimes base on the surface tension of HA and its sub-fractions.

\subsection{DLS and Zeta potential methodology}

The DLS measurement, with an operational range of $0.6 \sim 6000 \mathrm{~nm}$ was performed using the Malvern Zetasizer ZS instrument (Malvern Instruments Ltd, UK) equipped with a He-Ne laser of $633 \mathrm{~nm}$. The attenuator was adjusted to automatically respond to produce the optimum laser intensity based on the sample condition of HA sub-fractions. To reduce the possible light scattering, the detector position was set at an angle of $173^{\circ}$. The solutions of HA sub-fractions were poured into a cuvette with a plastic cap to avoid the volatilization at a concentration of $2000 \mathrm{mg} \cdot \mathrm{L}^{-1}$ with $0.1 \mathrm{~mol} \cdot \mathrm{L}^{-1} \mathrm{~K}_{2} \mathrm{HPO}_{4} / \mathrm{KH}_{2} \mathrm{PO}_{4}$ and $0.1 \mathrm{~mol} \cdot \mathrm{L}^{-1} \mathrm{NaCl}$ at $\mathrm{pH}=6.86$. Equilibrium time was retained inside the instrument for two minutes to reach a constant temperature of $25^{\circ} \mathrm{C}$ before detection. All solutions were filtered $0.45 \mu \mathrm{m} \mathrm{mem-}$ brane, twelve replicates were determined to reduce the statistic error, and 2 mins intervals were recorded for each replicate. The HA aggregation size was collected in PSD of intensity, volume, and number recorder according to the International Standard ISO13321, Methods for Determination of PSD.

The zeta potential of the HA solutions was measured at scattered light detected at an angle of $13^{\circ}$. The zeta potential was estimated from the electrophoretic mobility of particles according to Henry's equation and Smoluchowski approximation [41]. HA and its sub-fractions were determined at concentration of $2000 \mathrm{mg} \cdot \mathrm{L}^{-1}$ with $0.1 \mathrm{~mol} \cdot \mathrm{L}^{-1}$ $\mathrm{K}_{2} \mathrm{HPO}_{4} / \mathrm{KH}_{2} \mathrm{PO}_{4}$ and $0.1 \mathrm{~mol} \cdot \mathrm{L}^{-1} \mathrm{NaCl}$ at $\mathrm{pH}=6.86$.

\subsection{Gaussian distribution model}

Gaussian distribution model was applied to fit the PSD curves of HA sub-fractions with a second-derivative method. The number-based PSD curve was accomplished by use of the residual of the second derivative, and "Peak types" of fitting functions were set as "Gaussian" in GM to analyze the HA sub-fractions. Fitting peaks were optimized by modifying peak height, width, and shape until the correlation coefficient $\left(R^{2}\right)$ value between 
the original spectra and fitted curves was close to 1.0 corresponding to minimal variance (Eq. 2).

$$
y=B+\frac{A e^{\frac{-4 \ln 2(x-\mu)^{2}}{w^{2}}}}{w\left(\frac{\pi}{4 \ln 2}\right)^{1 / 2}}
$$

Where B is the baseline, A is the Gaussian peak area, w is Gaussian peak of width at half-height, $x$ is size of HA sub-fractions aggregates, $\mu$ is the location at the center of the peak of number-base PSDs of HA sub-fractions.

\section{Results}

The HA and its sub-fractions were characterized and reported previously as Chinese standard HA including elemental analysis, ${ }^{13} \mathrm{C}-\mathrm{NMR}$, etc. The content of carbon (C), hydrogen $(\mathrm{H})$, and nitrogen $(\mathrm{N})$ increased from $540.3-593.8 \mathrm{~g} \cdot \mathrm{kg}^{-1}$, from $33.8-66.0 \mathrm{~g}^{-\mathrm{kg}^{-1}}$, from 28.2-39.9 $\mathrm{g} \cdot \mathrm{kg}^{-1}$, while the content of oxygen $(\mathrm{O})$ decrease from $286.5-372.1 \mathrm{~g} \cdot \mathrm{kg}^{-1} \mathrm{from}$ HA1-HA6. The alkyl C, O-alkyl C, aromatic C and carbonyl C ranged 17.7-30.0\%, 16.7$23.94 \%, 30.4-43.2 \%, 14.4-23.9 \%$, respectively for HA sub-fractions [42]. According to the ${ }^{13} \mathrm{C}-\mathrm{NMR}$ spectra of HA and its sub-fractions (Table 1).

Table 1. The CMC values, elemental analysis, and ${ }^{13} \mathrm{C}$ NMR in area of HAs isolations from biomass and soil.

\begin{tabular}{|c|c|c|c|c|c|c|c|c|c|c|c|c|}
\hline Source & $\begin{array}{c}\mathrm{C} \\
(\mathrm{g} \cdot \mathrm{kg}- \\
1)\end{array}$ & $\begin{array}{c}\mathrm{H} \\
(\mathrm{g} \cdot \mathrm{kg} \\
\left.{ }^{1}\right)\end{array}$ & $\begin{array}{c}\mathrm{N} \\
(\mathrm{g} \cdot \mathrm{kg}- \\
1)\end{array}$ & $\begin{array}{c}\mathrm{O} \\
(\mathrm{g} \cdot \mathrm{kg} \\
1)\end{array}$ & $\begin{array}{l}\text { Alkyl } \\
\text { C (\%) }\end{array}$ & $\begin{array}{c}\text { O- } \\
\text { Alkyl } \\
\text { C (\%) }\end{array}$ & $\begin{array}{c}\text { Aromatic } \\
\text { C (\%) }\end{array}$ & $\begin{array}{c}\text { Carbonyl } \\
\text { C(\%) }\end{array}$ & HB/HI & $\begin{array}{c}\mathrm{CMC}^{\mathrm{b}} \\
\left(\mathrm{mg} \cdot \mathrm{L}^{-}\right. \\
1)\end{array}$ & $\begin{array}{l}\mathrm{CMC}^{\mathrm{c}} \\
\left(\mathrm{mg} \cdot \mathrm{L}^{-}\right. \\
1)\end{array}$ & References \\
\hline $\begin{array}{l}\text { Food wastes + } \\
\text { green wastes } \\
(1 / v / v)(15 d \\
\text { composted) }\end{array}$ & 599 & 66.6 & 59.9 & 270.0 & 45.2 & 21.1 & 21.6 & 12.1 & 2.01 & 403 & 497 & $\begin{array}{c}\text { Quagliotto, } \\
\text { et al. [7] }\end{array}$ \\
\hline $\begin{array}{l}\text { Urban green } \\
\text { wastes no } \\
\text { composted }\end{array}$ & 579 & 60.7 & 45.5 & 231.3 & 49.5 & 21.6 & 14.2 & 14.6 & 1.76 & 970 & 906 & $\begin{array}{c}\text { Montoneri, } \\
\text { et al. [43] }\end{array}$ \\
\hline $\begin{array}{c}\text { Green wastes } \\
\text { (start of aerobic } \\
\text { digestion) }\end{array}$ & 650 & 58.5 & 45.5 & 247.0 & 48.9 & 25.1 & 16.1 & 9.9 & 1.86 & 770 & 625 & $\begin{array}{c}\text { Savarino, et } \\
\text { al. [44] }\end{array}$ \\
\hline $\begin{array}{c}\text { Green wastes ( } 7 \mathrm{~d} \\
\text { digested) }\end{array}$ & 635 & 58.5 & 57.1 & 247.0 & 44.6 & 24.6 & 17.4 & 12 & 1.69 & 750 & 846 & $\begin{array}{c}\text { Savarino, et } \\
\text { al. [44] }\end{array}$ \\
\hline $\begin{array}{c}\text { Green wastes }(60 \mathrm{~d} \\
\text { digested })\end{array}$ & 604 & 50.8 & 42.3 & 302.0 & 43.5 & 26.6 & 19.3 & 10.5 & 1.69 & 730 & 892 & $\begin{array}{c}\text { Savarino, et } \\
\text { al. [44] }\end{array}$ \\
\hline $\begin{array}{c}\text { Food + green } \\
\text { wastes }(1 / 1-w / w) \\
\text { start of aerobic } \\
\text { digestion }\end{array}$ & 645 & 54.3 & 51.6 & 245.0 & 55.1 & 23.2 & 11 & 10.4 & 1.97 & 999 & 1057 & $\begin{array}{c}\text { Savarino, et } \\
\text { al. [44] }\end{array}$ \\
\hline $\begin{array}{c}\text { Food + green } \\
\text { wastes }(1 / 1-w / w) \\
7 \text { d digested }\end{array}$ & 627 & 62.7 & 53.3 & 257.0 & 53.8 & 24.4 & 12 & 8.8 & 1.98 & 1010 & 1005 & $\begin{array}{c}\text { Savarino, et } \\
\text { al. [44] }\end{array}$ \\
\hline $\begin{array}{c}\text { Food }+ \text { green } \\
\text { wastes } \\
(1 / 1-w / w) 60 \mathrm{~d} \\
\text { digested }\end{array}$ & 617 & 55.5 & 49.4 & 277.6 & 48.8 & 22.2 & 16.5 & 12.5 & 1.88 & 980 & 831 & $\begin{array}{c}\text { Savarino, et } \\
\text { al. [44] }\end{array}$ \\
\hline $\begin{array}{c}\text { Maize plant } \\
\text { residues }\end{array}$ & 548 & 64 & 41 & 342.0 & 26.8 & 42.3 & 21.1 & 9.9 & 0.92 & 1986 & 1950 & $\begin{array}{c}\text { Adani, et al } \\
{[30]}\end{array}$ \\
\hline HA-1 & 540.3 & 35.8 & 28.2 & 372.1 & 17.7 & 19.1 & 41.3 & 22.0 & 1.44 & 1016 & 977 & a \\
\hline HA-2 & 542.5 & 33.8 & 28.5 & 368.8 & 16.8 & 16.7 & 43.2 & 23.2 & 1.50 & 1024 & 910 & $\mathrm{a}$ \\
\hline
\end{tabular}




\begin{tabular}{cccccccccccccccccc}
\hline HA-3 & 541.6 & 39.2 & 36.2 & 362.3 & 19.9 & 17.1 & 39.1 & 23.9 & 1.44 & 833 & 941 & a \\
HA-4 & 567.2 & 52.9 & 42.7 & 307.3 & 25.6 & 22.1 & 31.9 & 20.4 & 1.35 & 779 & 741 & a \\
HA-5 & 579.8 & 60.7 & 38.4 & 299.0 & 29.9 & 25.3 & 30.4 & 14.4 & 1.52 & 343 & 372 & a \\
HA-6 & 593.8 & 66.0 & 39.9 & 286.5 & 30.0 & 23.9 & 30.4 & 15.7 & 1.52 & 216 & 136 & a \\
HA & 570.1 & 52.1 & 36.4 & 303.6 & 23.39 & 21.5 & 34.0 & 21.2 & 1.34 & 551 & 671 & a \\
\hline
\end{tabular}

a. data from this work.

b. CMC value experimentally determined.

c. Calculated by using the multiple regression model: $\mathrm{CMC}=18896-6.9 \times \mathrm{C}-296 \times$ alkyl C-331 $\times$ aromatic C $-17019 \times \mathrm{H} / \mathrm{C}+4054 \times \mathrm{HB} / \mathrm{HI}$. in which $\mathrm{CMC}$ is given in $\mathrm{mg} \cdot \mathrm{L}^{-1}, \mathrm{C}$ is given in $\mathrm{g} \cdot \mathrm{k} \mathrm{g}^{-1}$, alkyl $\mathrm{C}$ and aromatic $\mathrm{C}$ in $\%$ of the total ${ }^{13} \mathrm{C}-\mathrm{NMR}$ area, $\mathrm{HB} / \mathrm{HI}$ : ratio between hydrophobic vs. hydrophilic $\mathrm{C}$, in which, $\mathrm{HI}=$ percentage of hydrophilic carbon calculated as the sum of the13C $\mathrm{CP}$ MAS NMR area of (45-110) + (160-220) ppm and HB = percentage of hydrophobic carbon calculated as the sum of the13C CP MAS NMR area of (0-45) + (110-160) ppm.

\subsection{Surfactant properties of humic acid and its sub-fractions}

The surface tension decreased with the increase of the concentrations of HA sub-fractions from $0-2000 \mathrm{mg} \cdot \mathrm{L}^{-1}$ at $\mathrm{pH} 6.86$ with $0.1 \mathrm{~mol} \cdot \mathrm{L}^{-1}$ phosphate and $\mathrm{NaCl}$ as background ) (Figure 1). Two stages were clearly observed for both HA and its sub-fractions with surface tension from 45.6-72.4(Figure 1). The surface tensions decreased rapidly from 72.4 to $36.8 \mathrm{mN} \cdot \mathrm{m}^{-1}$ with the concentrations of HA sub-fractions from 0 to $2000 \mathrm{mg} \cdot \mathrm{L}^{-1}$. After $200 \mathrm{mg} \cdot \mathrm{L}^{-1} \mathrm{HA}$ sub-fractions were added, the surface tensions decreased gradually to 45.6$65.6 \mathrm{mN} \cdot \mathrm{m}^{-1}$ (Figure 1). The reducing surface tension of the aqueous solution increases the concentrations of HA sub-fractions. The same experimental phenomena have been reported before that samples were Aldrich HA, Suwannee River HA from IHSS, organic compost, and soil, etc. [4, 5, 19, 30, 44, 45]. For example, the surface tension of HA subfractions at about $2000 \mathrm{mg} / \mathrm{L}$ was comparable with Aldrich HA $\left(\sim 50 \mathrm{mN} \cdot \mathrm{m}^{-1}\right)$ [4], Elliott soil HA $\left(46 \mathrm{mN} \cdot \mathrm{m}^{-1}\right)[29]$, as well as HAs from surface soil of southern Chile $\left(\sim 45 \mathrm{mN} \cdot \mathrm{m}^{-1}\right)$ [19]. This phenomenon could be attributed to the self-assembly into an aggregation of HA as a natural surfactant, and the variation of HA aggregation size was also discussed in section 3.3 (Figure. 1).

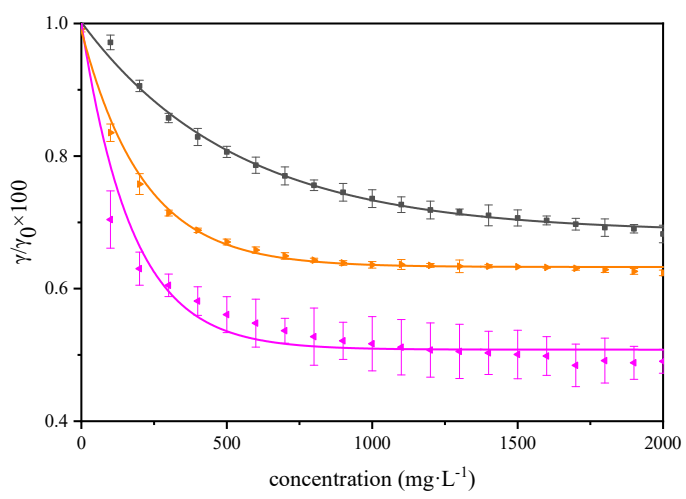

Figure 1. The reduction rate of surface tension with the concentration of HA1, HA6, and HA HA1, - HA, 4 HA6. The solid lines were fitted with exponential function).

The curves of surface tension vs. concentration of HA sub-fractions were well fitted by the least squares method using an exponential model with $\mathrm{R}^{2}$ from 0.945 to 0.996 (Eq. 
1). The $\Delta \gamma$ ranged from $22.9-35.7 \mathrm{mN} \cdot \mathrm{m}^{-1}$ in order to, HA6 $>$ HA3 $>$ HA2 $>$ HA5 $>$ HA4 $>$ HA1. Previous researchers reported that the $\Delta \gamma$ of surfactant was related to due to carbon atoms in a straight-chain hydrophobic group [21]. Therefore, the difference $\Delta \gamma$ of HA subfractions may be due to it's the content of carbon atoms in a straight-chain hydrophobic group. The $A$ ranged from 0.0018 to 0.0075 for HA1-HA6, among HA5-HA6 > HA1-4 that suggest the later isolated HAs had more efficiency reach $\gamma_{\text {plateaus }}$ (Table 1$)$.

\subsection{The CMC of $H A$ and its sub-fractions}

The CMC is an important index to measure the surface activity of HA. The CMC of HA sub-fractions ranged from $216-1024 \mathrm{mg} \cdot \mathrm{L}^{-1}$ according to surface tension detected by Wilhelmy method, in order of HA1 $\approx$ HA2 $>$ HA3 $>$ HA4 $>$ HA5 $>$ HA6 (Figure 2). This result consistent with previous research reports, HA derived from urban green wastes $\left(970 \mathrm{mg} \cdot \mathrm{L}^{-1}\right)$ [43], green waste $\left(730-770 \mathrm{mg} \cdot \mathrm{L}^{-1}\right)$ [44], green and food waste $(403-1010 \mathrm{mg} \cdot \mathrm{L}-$ $\left.{ }^{1}\right)$ [44], southern Chile soil of uncultivated pasture areas (800-3300 $\left.\mathrm{mg} \cdot \mathrm{L}^{-1}\right)$ [19], Nagano and Hyogo Prefecture soil of Japan (289-777 $\left.\mathrm{mg} \cdot \mathrm{L}^{-1}\right)$ [20].
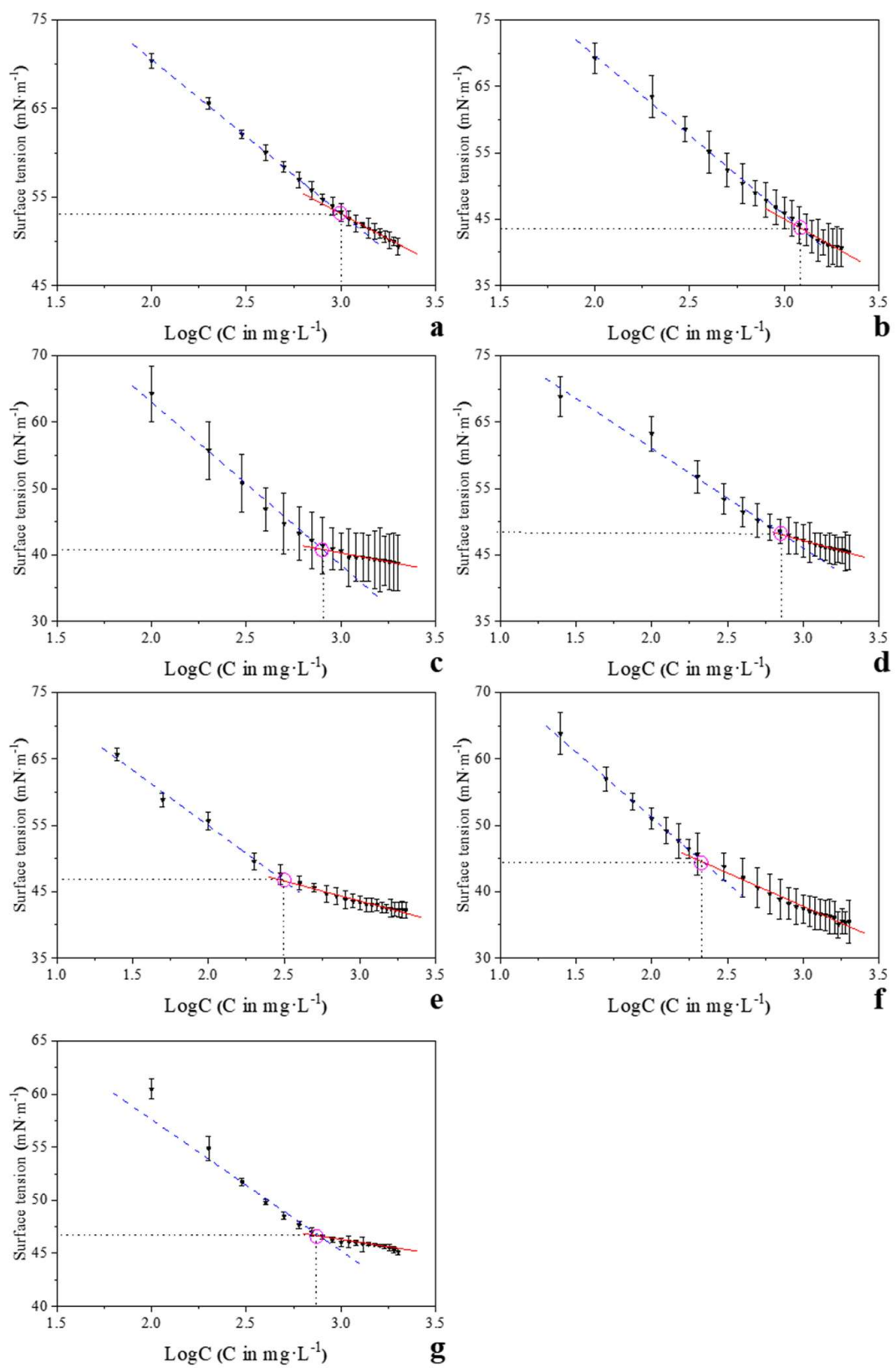
Figure 2. Surface tension versus $\mathrm{HA}$ and its sub-fractions concentrations $\left(\mathrm{mg} \cdot \mathrm{L}^{-1}\right)$. CMC was calculated from the intersection of the premicellar and postmicellar straight lines (a. HA1; b. HA2; c. HA3; d. HA4; e. HA5; f. HA6; g. HA. --- premicellar; - postmicellar).

Table 2. Fitting exponential function surface tension values of HA sub-fractions.

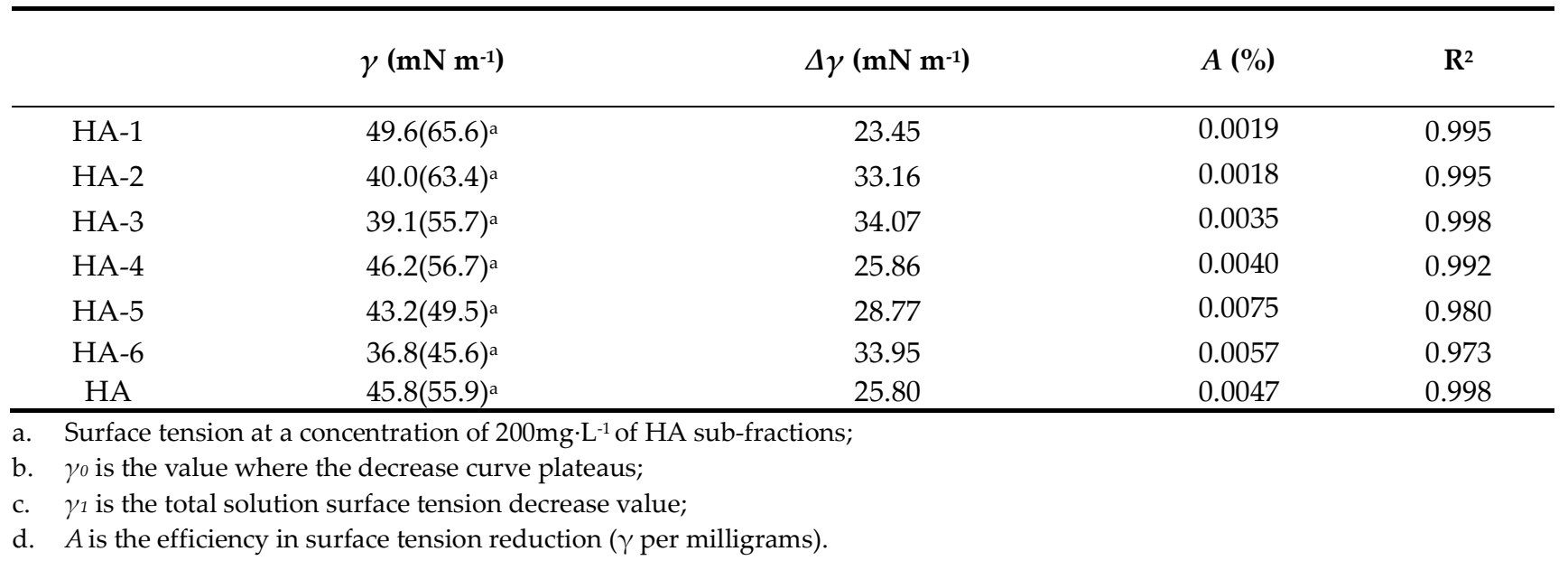

To compare the performance of HA in reducing surface tension, it is necessary to distinguish between the $A$ and $\Delta \gamma$ of an aqueous solution. No correlation was obtained between CMC and $\Delta \gamma$ for HA sub-fractions. The concentration-forming micelles (CMC) have no relationship with $\Delta \gamma$ for $\mathrm{HA}$ and its sub-fractions. The insignificant correlation might be attributed to the different structures or composition of HAs regulating micelle formation and maximum reduction in tension, which should be further investigated [21].

There was significant relationship for CMC with alkyl C with $\mathrm{R}^{2} 0.872(p<0.05)$, Oalkyl C with $\mathrm{R}^{2} 0.748(p<0.05)$, aromatic C with $\mathrm{R}^{2} 0.781(p<0.05)$, and carbonyl C with $\mathrm{R}^{2}$ $0.764(p<0.05)$, respectively in Figure S1. The results also consistent with previous researchers, Quadri, et al. [5] discovered the value of CMC related to the content of alkyl C for the HA isolated from organic compost. The significant correlation should be attributed to the increase of the free energy of the water/surfactant-like system and the reduction of anticipating the process of micellization by a greater content of alkyl chains and aromatic HA molecule [5].

The CMC obtained was significantly relationship for $\mathrm{N}$ with $\mathrm{R}^{2}=0.538 \quad(p<0.5)$. This result was also reported by Quadri, et al. [5], who focused on lignocelluloses waste compost. The researcher considers that maybe amide molecules mutual repulsion polar groups, thereby reducing the work required for micellization [46]. The CMC also correlation relationship for $C\left(\mathrm{R}^{2}=0.900, p<0.5, \mathrm{n}=7\right)$ and $\mathrm{H}\left(\mathrm{R}^{2} 0.912, p<0.5, \mathrm{n}=7\right)$ those represents the degree of condensation between HA molecules [47]. The result suggests CMC of HA maybe not only with the hydrophobic group but also with the condensation degree of molecules.

Multiple regression models were applied to calculate the $\mathrm{CMC}$ according to the parameters of HAs including, $\mathrm{C}$, alkyl $\mathrm{C}$, aromatic $\mathrm{C}, \mathrm{H} / \mathrm{C}$, and $\mathrm{HB} / \mathrm{HI}$, the $\mathrm{HI}$ was the percentage of hydrophilic carbon calculated as the sum of (45-110 ppm) and (160-220 ppm), and HB was the percentage of hydrophobic carbon calculated as the sum of (0-45 ppm) and (110-160 ppm) in ${ }^{13} \mathrm{C}$ NMR. Sixteen samples were used to update the CMC prediction equation, including HA derived from soil, green waste, and maize plant residues [29, 30, $43,44]$. For the 16 samples, the contents of $\mathrm{C}$, alkyl C, aromatic C, H/C, and HB/HI ranged

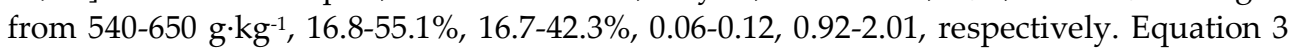
was obtained as $\mathrm{CMC}=18896-6.9 \times \mathrm{C}-296 \times a l k y l \quad \mathrm{C}-331 \times$ aromatic C$17019 \times \mathrm{H} / \mathrm{C}+4054 \times \mathrm{HB} / \mathrm{HI}$. The $\mathrm{H} / \mathrm{C}$ can indicate the degree of intermolecular condensation of HA [48]. Therefore, the equation suggests that the value of CMC was not only related 
to the hydrophobic fractions of HA but also related to the degree of intermolecular condensation.

The obtained model was quite qualified for the prediction of the CMC of HAs samples in biomasses and soil. Compared to previous reports, the model added a new sample source, soil HA. The $\mathrm{R}^{2}$ (0.909) and n (16) of model were greater than previous reports. For example, HAs derived from lignocelluloses waste, lignocelluloses plus food wastes, and Aldrich HA (Eq. S1, n =6, $\mathrm{R}^{2}=0.77$ ) [5], lignocelluloses waste, lignocelluloses plus food wastes, maize plant residue, as well as Aldrich HA (Eq. S2, n =7, R2 =0.90) [30], urban green wastes, lignocelluloses waste, and green wastes, etc. (Eq. S3, n = 13, R2 = 0.878) [3] (Table S1). The average absolute error (AAE) of CMC was $12.95 \%$, indicating the predicted results were close to the measured results, and the average biased error (ABE) of $\mathrm{CMC}$ was $0.47 \%$, showing the accuracy of model prediction [49]. The predicted CMCs were within the $95 \%$ prediction intervals of HAs samples (Figure 3 ) that suggests predicted results were credible. The model proposed indicates that the hydrophobicity/hydrophilicity group and degree condensation of the HA molecule was the principal responsible for the CMC.

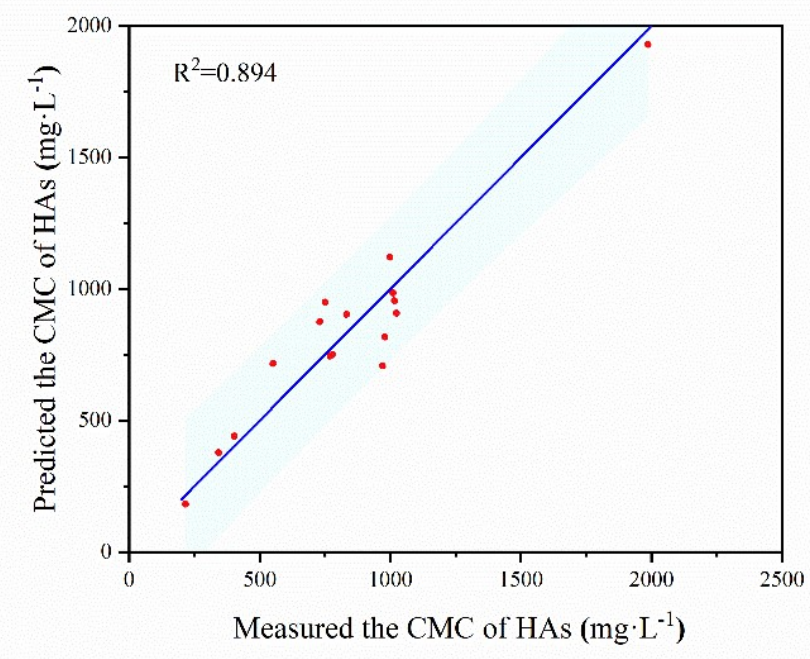

Figure 3. Predicted CMC of HA sub-fractions versus their observed CMC of HAs isolated from biomass and soil with a $95 \%$ confidence interval.

\subsection{HA sub-fractions Zeta potential and size characteristic}

The value of the zeta potential $(\zeta)$ became more negative from -4.2 to $-46.7 \mathrm{mV}$ as the concentration of HA increased from 10 to $2000 \mathrm{mg} \cdot \mathrm{L}^{-1}$ at $\mathrm{pH}=6.86$ (Figure S2). The negative relationship between $\zeta$ and the concentration of HAs was also observed for Aldrich HA detected by Esfahani, et al. [32]. Previous researches documented that the colloidal was stability when $\zeta$ were less than $-30 \mathrm{mV}$ in an aqueous solution. The $\zeta$ less than -30 indicated the stable colloidal at a concentration of $2000 \mathrm{mg} \cdot \mathrm{L}^{-1}$ for $\mathrm{HA} \mathrm{sub}$-fraction at $\mathrm{pH}$ $=6.86$. Therefore, the concentration of $2000 \mathrm{mg} \cdot \mathrm{L}^{-1}$ was used to investigate the possible effects of $\mathrm{pH}$ and variation of PSDs for both HA and its sub-fractions. The $\zeta$ of HA and its sub-fractions ranged from -44.2 to $-50.2 \mathrm{mV}$ at $\mathrm{pH} 6.86$ with concentration at $2000 \mathrm{mg} / \mathrm{L}$, in order of HA $1>$ HA $3>$ HA $2>$ HA $5>$ HA $6>$ HA4. The $\zeta$ were significantly related to the content of carboxylic groups in HA and its sub-fractions $(p<0.20)$. The relationship between $\zeta$ and the content of the carboxylic group was observed for HA derived from Rendzic Leptosol and Suwannee River HA from IHSS, indicating the carboxylic group was the main factor that controlled the surface charge of HA [50].

The particle size of HA aggregation previously reported as Z-average diameter ranged from 108 to $187 \mathrm{~nm}$ for HA and its sub-fractions according to intensity-based PSDs. The range of Z-average sizes of HA sub-fractions was comparable to 185-280 nm of HA 
derived from peat [35], Aldrich HA [32], and Suwannee River HA from IHSS [34]. Intensity-, volume-, and number-based PSDs were obtained for both HA and its subfractions by DLS. Three peaks were observed in intensity-based PSDs of HA and its sub-fractions, about $10 \mathrm{~nm}, 280 \mathrm{~nm}$, and $5000 \mathrm{~nm}$ (Figure S3). The largest size of HA sub-fractions ( 5000 $\mathrm{nm})$ was due to the abiotic self-assembled of HA molecules after filtered with $0.45 \mu \mathrm{m}$ (equal to $450 \mathrm{~nm}$ ) membrane (Figure S3-4). The larger aggregation for HA (more than 1000 $\mathrm{nm}$ ) was also reported by Esfahani, et al. [32], who observed the aggregation of Suwannee River HA from IHSS and Aldrich HA in intensity-based PSDs. In addition, the intensity based on Z-average diameter was comparable to other reports in the literature, while Zaverage was based on a monomodal hypothesis that cannot fully reflect the truly polymodal character of HA $[32,36,51]$.

Table 3. Assignments and relative area of Gaussian fitting peaks from number-based PSDs of HA sub-fractions with its Z-average size at concentrations of $2000 \mathrm{mg} \cdot \mathrm{L}^{-1}$.

\begin{tabular}{cccccccccccccc}
\hline & $\begin{array}{c}\text { Peak 1 } \\
(\mathbf{n m})\end{array}$ & $\begin{array}{c}\text { W } \\
\mathbf{( n m})\end{array}$ & $\begin{array}{c}\text { Percent } \\
\mathbf{( \% )}\end{array}$ & $\begin{array}{c}\text { Peak 2 } \\
\mathbf{( n m})\end{array}$ & $\begin{array}{c}\text { W } \\
\mathbf{( n m )}\end{array}$ & $\begin{array}{c}\text { Percent } \\
\mathbf{( \% )}\end{array}$ & $\begin{array}{c}\text { Peak 3 } \\
\mathbf{( n m )}\end{array}$ & $\begin{array}{c}\text { W } \\
(\mathbf{n m})\end{array}$ & $\begin{array}{c}\text { Percent } \\
\mathbf{( \% )}\end{array}$ & $\begin{array}{c}\text { Peak 4 } \\
(\mathbf{n m})\end{array}$ & $\begin{array}{c}\text { W } \\
(\mathbf{n m})\end{array}$ & $\begin{array}{c}\text { Percent } \\
(\mathbf{\%})\end{array}$ \\
\hline HA1 & 1.0 & 0.44 & 3.30 & 1.9 & 1.23 & 16.85 & 3.8 & 2.75 & 44.69 & 10.2 & 7.44 & 35.16 \\
HA2 & 5.3 & 1.97 & 2.46 & 8.2 & 4.58 & 2.85 & 45.9 & 36.16 & 67.73 & 78.1 & 55.46 & 26.96 \\
HA3 & 5.6 & 2.91 & 18.60 & 10.6 & 6.08 & 40.37 & 14.6 & 7.93 & 30.29 & 21.1 & 12.36 & 11.00 \\
HA4 & 2.1 & 0.80 & 3.51 & 4.5 & 18.91 & 24.08 & 6.3 & 3.67 & 50.87 & 9.0 & 5.43 & 21.55 \\
HA5 & 5.0 & 2.58 & 4.90 & 7.3 & 4.20 & 10.36 & 28.7 & 16.18 & 41.18 & 41.8 & 26.47 & 43.56 \\
HA6 & 2.1 & 1.15 & 3.43 & 4.8 & 2.58 & 20.22 & 6.8 & 4.21 & 37.82 & 11.0 & 8.25 & 38.54 \\
\hline
\end{tabular}

W - the peak width at half-height;

Peak - peak center location;

Percent - peak area percentage. 

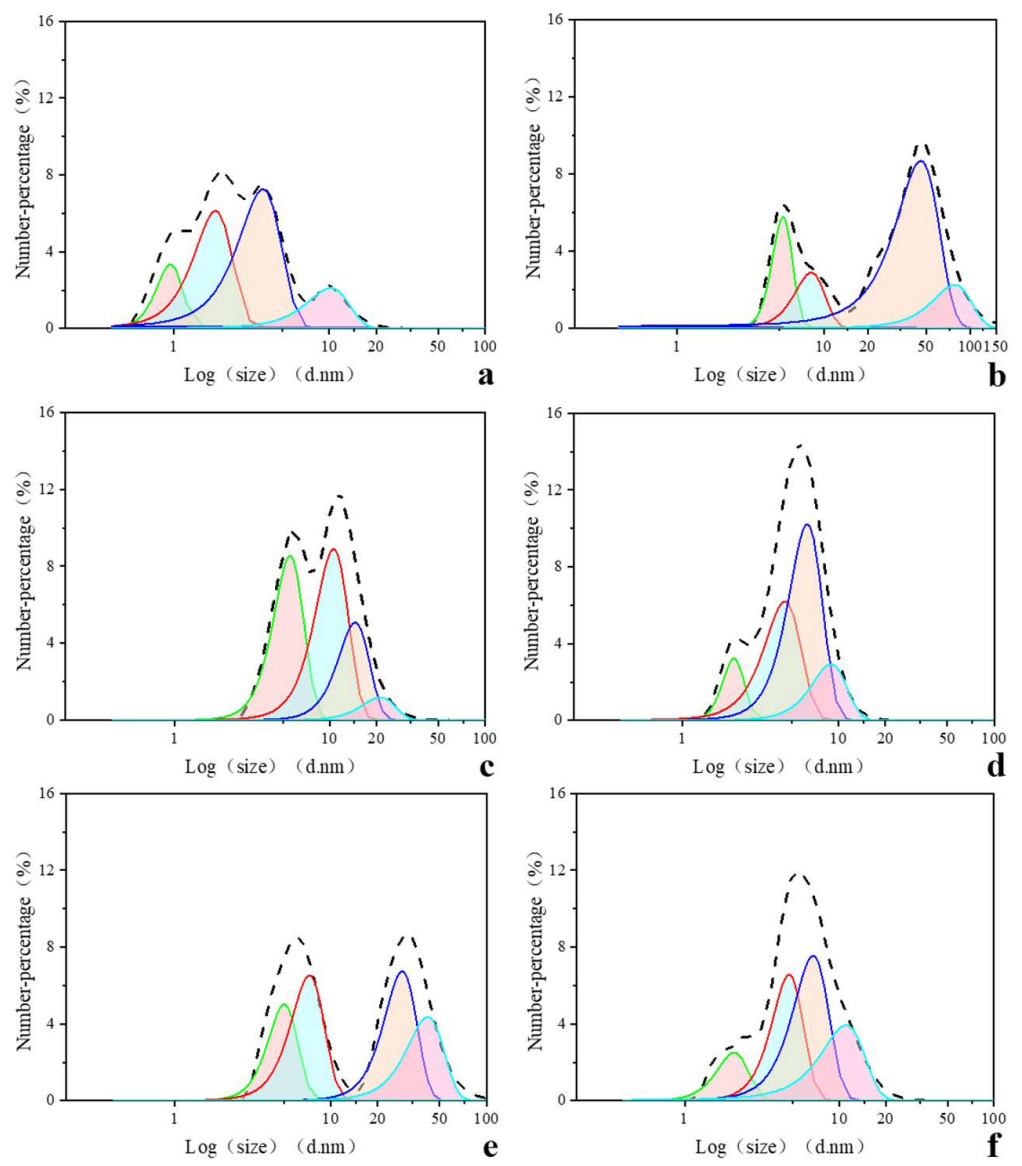

Figure 4. Gaussian fitting peaks of number PSDs of six sub-fractions for HA at concentrations of $2000 \mathrm{mg} \cdot \mathrm{L}^{-1}$ (a. HA1; b. HA2; c. HA3; d. HA4; e. HA5; f. HA6. --- measurement curve. $\mathbf{\square}$ peak1; peak2; $\mathbf{\square}$ peak3; $\boldsymbol{\square}$ peak4).

The number-base PSDs can reflect the aggregation distribution characteristics of HA sub-fractions. The size distributions of HA1-6 were $0.6-15.7 \mathrm{~nm}, 3.6-122 \mathrm{~nm}, 3.1-24.4 \mathrm{~nm}$, 1.5-13.5 nm, 3.1-68.1 nm, 1.3-18.2 nm, respectively according to number-based PSDs (Figure 4). The size distributions of HA2 and HA5 were 3-5 times wider than that of other subfractions. The larger distributions were like to the complexity of HA structure of HA2 and HA5, which should be further studied in the future. Three peaks and a clear shoulder were observed in number-based PSDs of HA1 including the maximum peak $(\sim 2.0 \mathrm{~nm})$ with shoulder $(\sim 1 \mathrm{~nm})$, the second maximum peak $(\sim 3.6 \mathrm{~nm})$, and the third maximum peak $(\sim 10.1 \mathrm{~nm})$. Two peaks, the maximum peak $(\sim 5.6 \mathrm{~nm})$ and the second maximum peak $(\sim 43.8 \mathrm{~nm})$ were observed in number-based PSDs of HA2. Two primary peaks, the maximum peak $(\sim 5.6 \mathrm{~nm})$ and the second maximum peak $(11.7 \mathrm{~nm})$ were observed in numberbased PSDs of HA3. One primary peak $(\sim 5.6 \mathrm{~nm})$ with shoulder $(\sim 2.0 \mathrm{~nm})$ was observed in number-based PSDs of HA4. Two primary peaks including the maximum peak $(\sim 32.7$ $\mathrm{nm})$, the second maximum peak $(\sim 6.5 \mathrm{~nm})$ were observed in number-based PSDs of HA5; One primary peak, maximum peak $(\sim 4.85 \mathrm{~nm})$ that have a clear shoulder $(\sim 1.5 \mathrm{~nm})$ were observed in number-based PSDs of HA6. Those shoulders were likely due to overlapping aggregation for HA1, HA4, and HA6 (Figure 4).

Gaussian peak fitting was applied to identify the possible information of overlapping PSDs for both HA and its sub-fractions. The contributions of individual four peaks were identified in number-based PSD of HA sub-fractions using Gaussian peak fitting with $\mathrm{R}^{2}$ ranged from 0.990 to 0.999 . According to Gaussian peak fitting of number-based PSDs, six clusters of peaks center location were obtained for $2 \pm 1 \mathrm{~nm}, 5 \pm 2 \mathrm{~nm}, 10 \pm 3 \mathrm{~nm}, 21 \pm 8$ 
$\mathrm{nm}, 40 \pm 10 \mathrm{~nm}$, and > $50 \mathrm{~nm}$ (name as C1-6) for both HA and its sub-fractions. Four Gaussian peaks located in $\mathrm{C} 1$ including peak 1 of HA1 with a number percentage of $3.3 \%$, peak 2 of HA1 with number percentage of $16.85 \%$, peak 1 of HA4 with number percentage of $3.51 \%$, peak 1 of HA6 with number percentage of $3.43 \%$. Eight Gaussian peaks located in C2 including peak 1 of HA1 with number percentage of $44.69 \%$, peak 1 of HA2 with number percentage of $2.46 \%$, peak 1 of HA3 with number percentage of $18.6 \%$, peak 2 of HA4 with number percentage of $24.08 \%$, peak 3 of HA4 with number percentage of $50.87 \%$, peak 1 of HA 5 with number percentage of $4.90 \%$, peak 2 of HA6 with number percentage of $20.22 \%$, peak 3 of HA6 with number percentage of $67.82 \%$. Six Gaussian peaks located in C3 including peak 4 of HA1 with number percentage of $35.16 \%$, peak 2 of HA2 with number percentage of $2.85 \%$, peak 2 of HA3 with number percentage of $40.37 \%$, peak 4 of HA4 with number percentage of $21.55 \%$, peak 2 of HA5 with number percentage of $10.36 \%$, peak 4 of HA6 with number percentage of $38.54 \%$. Three Gaussian peaks located in C4 including peak 3 of HA3 with a number percentage of $11.00 \%$, peak 4 of HA3 with number percentage of $30.29 \%$, peak 3 of HA5 with a number percentage of $41.18 \%$. Two Gaussian peaks located in C5 including peak 3 of HA2 with a number percentage of $67.73 \%$, peak 4 of HA5 with number percentage of $43.56 \%$. One Gaussian peak located in C6 including peak 4 of HA2 with a number percentage of $26.96 \%$ (Figure 4$)$. The C2 ( 5 $\mathrm{nm}$ ) has the maximum number percentage for Gaussian peak 33.92\%, while C6 ( 78 nm) has the minimum number percentage of $4.49 \%$. According to previous studies, the average size of HA is affected by cation concentration and type, $\mathrm{pH}$, salinity, and residence time [36]. The HA sub-fractions represent different fractions of soil humic substances those have different structures. Therefore, the difference in the structure of HA sub-fractions may be the cause of difference on the Gaussian peaks of number-base PSDs, which need further study.

The Gaussian peak with the maximum size appeared for $45.9 \mathrm{~nm}$, and the minimum size appeared for $5.3 \mathrm{~nm}$ in number-based PSDs. The maximum value of peak width at half-height of Gaussian peak was observed from HA 2 with the width of $55.46 \mathrm{~nm}$, and the highest Gaussian peak was observed for HA 2 with a number percentage of $67.73 \%$. (Figure S5). A previous study reported that the hydrodynamic radii were related to molecular mass according to the analysis of Aldrich HA and two other HSs derived from peat and compost with ultrafiltration combined with DLS [52]. The various distribution of Gaussian peaks should be attributed to the complex structure and complicated conformation of HA molecules.

The maximum values of peak width at half-height were $7.44 \mathrm{~nm}$ (HA1), $55.46 \mathrm{~nm}$ (HA2), $12.36 \mathrm{~nm}$ (HA3), $18.91 \mathrm{~nm}$ (HA4), $26.47 \mathrm{~nm}$ (HA5), $8.25 \mathrm{~nm}$ (HA6), respectively. The full width at half maxima of HA2 and HA5 was greater than that of other HA subfractions (Figure. 4), it suggests the aggregate size distribution of HA2 and HA5 is more extensive wider than other HA sub-fractions. This may be due to the inconsistency of the components and structures of the HA sub-fractions, requiring further study.

\section{Conclusion}

The surface tension of HA and its sub-fractions reduced from $72.4 \mathrm{mN} \cdot \mathrm{m}^{-1}$ to 36.8 $\mathrm{mN} \cdot \mathrm{m}^{-1}$ with the increasing concentration from 0 to $2000 \mathrm{mg} \cdot \mathrm{L}^{-1}$ with exponential model. The difference maximum surface tensions of HA sub-fractions may be due to it's the content of carbon atoms in a straight-chain hydrophobic group. The CMC of HA sub-fractions ranged from 216-1024 $\mathrm{mg} \cdot \mathrm{L}^{-1}$, fitting the new multiple linear regression equation to predicted and analyzed CMC of HA. The updated multiple linear regression equation, CMC $=18896-6.9 \times \mathrm{C}-296 \times$ alkyl C-331 $\times$ aromatic $\mathrm{C}-17019 \times \mathrm{H} / \mathrm{C}+4054 \times \mathrm{HB} / \mathrm{HI}$ was documented to predicted $\mathrm{CMC}$ of HAs reported by previous researchers and HA subfractions. This model suggests that besides the hydrophilic/hydrophobic groups of HA, the degree of intermolecular condensation also has an important effect on the CMC of HA. The maximum particle size was $5000 \mathrm{~nm}$ after filtered by a membrane with pore size of $450 \mathrm{~nm}$, indicating HA and its sub-fractions could progressed self-assembly at $\mathrm{pH}$ 6.86. The main PSDs of soil HA aggregates was distributed in the region within $100 \mathrm{~nm}$. The aggregate 
sizes of number-base PSDs were mainly in six clusters including $2 \pm 1 \mathrm{~nm}, 5 \pm 2 \mathrm{~nm}, 10 \pm$ $3 \mathrm{~nm}, 21 \pm 8 \mathrm{~nm}, 40 \pm 10 \mathrm{~nm}$, and > $50 \mathrm{~nm}$ analyzed by Gaussian model. However, the micellar structure of HA sub-fractions aggregates is still not clearly understood, and further studies are required by experiment condition, such as temperature, $\mathrm{pH}$ etc. The possible CMC prediction and aggregate size could be helpful to understand hyperfine structure of HAs and the predict the environmental behaviors of HA in aquatic systems.

Materials: The following are available online at www.mdpi.com/xxx/s1, Figure S1: title, Table S1: title, Video S1: title.

Author Contributions: Conceptualization, BY; Methodology, BY, TS Validation, TS; Data Curation, TS, WX, LT, SF, HN; Writing - Original Draft Preparation, TS.; Writing - Review \& Editing, BY, TW.

Funding: This work was financially supported by the National Natural Science Foundation of China (Nos. 41703123), and the Fundamental Research Funds for the Central Public-interest Scientific Institution (No. 2019YSKY-006).

Data Availability Statement: The data presented in this study are available upon request from the corresponding author.

Institutional Review Board Statement: Informed consent was obtained from all subjects involved in the study.

Informed Consent Statement: Not applicable.

Conflicts of Interest: The authors declare no conflict of interest. 


\section{Appendix A}

\section{References}

1. Bai, Y.; Wu, F.; Xing, B.; Meng, W.; Shi, G.; Ma, Y.; Giesy, J. P., Isolation and characterization of Chinese standard fulvic acid sub-fractions separated from forest soil by stepwise elution with pyrophosphate buffer. Scientific Reports 2015, 5, 8723. https://doi.org/10.1038/srep08723.

2. Li, T.; Song, F.; Zhang, J.; Liu, S.; Xing, B.; Bai, Y., Pyrolysis characteristics of soil humic substances using TG-FTIR-MS combined with kinetic models. Science of The Total Environment 2020, 698, 134237. https://doi.org/10.1016/j.scitotenv.2019.134237.

3. Salati, S.; Papa, G.; Adani, F., Perspective on the use of humic acids from biomass as natural surfactants for industrial applications. Biotechnology Advances 2011, 29, (6), 913-22. https://doi.org/10.1016/j.biotechadv.2011.07.012.

4. Guetzloff, T. F.; Rice, J. A., Does humic acid form a micelle? Science of the Total Environment 1994, 152, (1), 31-35. https://doi.org/10.1016/0048-9697(94)90548-7.

5. Quadri, G.; Chen, X.; Jawitz, J. W.; Tambone, F.; Genevini, P.; Faoro, F.; Adani, F., Biobased surfactant-like molecules from organic wastes: the effect of waste composition and composting process on surfactant properties and on the ability to solubilize tetrachloroethene (PCE). Environmental Science \& Technology 2008, 42, (7), 2618-2623. https://doi.org/10.1021/es702144t.

6. Kerner, M.; Hohenberg, H.; Ertl, S.; Reckermann, M.; Spitzy, A., Self-organization of dissolved organic matter to micelle-like microparticles in river water. Nature 2003, 422, (6928), 150-154. https://doi.org/10.1038/nature01469.

7. Quagliotto, P.; Montoneri, E.; Tambone, F.; Adani, F.; Gobetto, R.; Viscardi, G., Chemicals from wastes: compost-derived humic acid-like matter as surfactant. Environmental Science \& Technology 2006, 40, (5), 1686-1692. https://doi.org/10.1021/es051637r.

8. Sierra, M.; Rauen, T.; Tormen, L.; Debacher, N.; Soriano-Sierra, E., Evidence from surface tension and fluorescence data of a pyreneassisted micelle-like assemblage of humic substances. Water Research 2005, 39, (16), 3811-3818. https://doi.org/10.1016/j.watres.2005.07.005.

9. Ying, G., Fate, behavior and effects of surfactants and their degradation products in the environment. Environment International 2006, 32, (3), 417-431. https://doi.org/10.1016/j.envint.2005.07.004.

10. Savarino, P.; Montoneri, E.; Biasizzo, M.; Quagliotto, P.; Viscardi, G.; Boffa, V., Upgrading biomass wastes in chemical technology. Humic acid - like matter isolated from compost as chemical auxiliary for textile dyeing. Journal of Chemical Technology \& Biotechnology: International Research in Process, Environmental \& Clean Technology 2007, 82, (10), 939-948. https://doi.org/10.1002/jctb.1767.

11. Schwitzguébel, J.-P.; Aubert, S.; Grosse, W.; Laturnus, F., Sulphonated Aromatic Pollutants: Limits of Microbial Degradability and Potential of Phytoremediation. Environmental Science \& Pollution Research International 2002. https://doi.org/10.1007/BF02987317.

12. Garc1a, M.; Ribosa, I.; Guindulain, T.; Sanchez-Leal, J.; Vives-Rego, J., Fate and effect of monoalkyl quaternary ammonium surfactants in the aquatic environment. Environmental Pollution 2001, 111, (1), 169-175. https://doi.org/10.1016/S0269-7491(99)00322-X.

13. Diodovich, C.; Ferrario, D.; Casati, B.; Malerba, I.; Marafante, E.; Parent-Massin, D.; Gribaldo, L., Sensitivity of human cord blood cells to tetrachloroethylene: cellular and molecular endpoints. Archives of Toxicology 2005, 79, (9), 508-514. https://doi.org/10.1007/s00204-005$\underline{0662-8}$.

14. Moran, M. J.; Zogorski, J. S.; Squillace, P. J., Chlorinated solvents in groundwater of the United States. Environmental Science \& Technology 2007, 41, (1), 74-81.

15. Holmberg, K., Natural surfactants. Current Opinion in Colloid \& Interface Science 2001, 6, (2), 148-159. https://doi.org/10.1016/S13590294(01)00074-7.

16. Diallo, M. S.; Abriola, L. M.; Weber, W. J., Solubilization of nonaqueous phase liquid hydrocarbons in micellar solutions of dodecyl alcohol ethoxylates. Environmental Science \& Technology 1994, 28, (11), 1829-1837. https://doi.org/10.1021/es00060a012.

17. Das, P.; Mukherjee, S.; Sen, R., Improved bioavailability and biodegradation of a model polyaromatic hydrocarbon by a biosurfactant producing bacterium of marine origin. Chemosphere 2008, 72, (9), 1229-1234. https://doi.org/10.1016/j.chemosphere.2008.05.015.

18. Ke, L.; Bao, W.; Chen, L.; Wong, Y. S.; Tam, N., Effects of humic acid on solubility and biodegradation of polycyclic aromatic hydrocarbons in liquid media and mangrove sediment slurries. Chemosphere 2009, 76, (8), 1102-1108. https://doi.org/10.1016/i.chemosphere.2009.04.022. 
19. Urdiales, C.; Sandoval, M. P.; Escudey, M.; Pizarro, C.; Knicker, H.; Reyes-Bozo, L.; Antilén, M., Surfactant properties of humic acids extracted from volcanic soils and their applicability in mineral flotation processes. Journal of Environmental Management 2018, 227, 117123. https://doi.org/10.1016/j.jenvman.2018.08.072.

20. Kawahigashi, M.; Fujitake, N., Surface-active properties of particle size fractions in two humic acids. Soil Science and Plant Nutrition 1998, 44, (4), 497-505. https://doi.org/10.1134/S1061933X09050226.

21. Rosen, M. J.; Kunjappu, J. T., Surfactants and interfacial phenomena. John Wiley \& Sons: 2012.202-272

22. Song, F.; Wu, F.; Feng, W.; Liu, S.; He, J.; Li, T.; Zhang, J.; Wu, A.; Amarasiriwardena, D.; Xing, B., Depth-dependent variations of dissolved organic matter composition and humification in a plateau lake using fluorescence spectroscopy. Chemosphere 2019, 225, 507516. https://doi.org/10.1016/j.chemosphere.2019.03.089.

23. Song, F.; Wu, F.; Guo, F.; Wang, H.; Feng, W.; Zhou, M.; Deng, Y.; Bai, Y.; Xing, B.; Giesy, J. P., Interactions between stepwise-eluted sub-fractions of fulvic acids and protons revealed by fluorescence titration combined with EEM-PARAFAC. Science of The Total Environment 2017, 605, 58-65. https://doi.org/10.1016/j.scitotenv.2017.06.164.

24. Zhang, J.; Song, F.; Li, T.; Xie, K.; Yao, H.; Xing, B.; Li, Z.; Bai, Y., Simulated photo-degradation of dissolved organic matter in lakes revealed by three-dimensional excitation-emission matrix with regional integration and parallel factor analysis. Journal of Environmental Sciences 2020, (4). https://doi.org/10.1016/j.jes.2019.11.019.

25. Myers, J. L.; Well, A.; Lorch, R. F., Research design and statistical analysis. Routledge: 2010;

26. Aiken, L. S.; West, S. G.; Pitts, S. C.; Baraldi, A. N.; Wurpts, I. C., Multiple linear regression. Handbook of Psychology, Second Edition 2012, 2. https://doi.org/10.1002/9781118133880.hop202018.

27. Qian, X., Statistical Analysis and Evaluation of the Advanced Biomass and Natural Gas Co-Combustion Performance. 2019.

28. Uyanık, G. K.; Güler, N., A study on multiple linear regression analysis. Procedia-Social and Behavioral Sciences 2013, 106, $234-240$. https://doi.org/10.1016/j.sbspro.2013.12.027.

29. Liang, Y.; Britt, D. W.; McLean, J. E.; Sorensen, D. L.; Sims, R. C., Humic acid effect on pyrene degradation: finding an optimal range for pyrene solubility and mineralization enhancement. Applied Microbiology and Biotechnology 2007, 74, (6), 1368-1375. https://doi.org/10.1007/s00253-006-0769-8.

30. Adani, F.; Tambone, F.; Davoli, E.; Scaglia, B., Surfactant properties and tetrachloroethene (PCE) solubilisation ability of humic acid-like substances extracted from maize plant and from organic wastes: A comparative study. Chemosphere 2010, 78, (8), 1017-1022. https://doi.org/10.1016/j.chemosphere.2009.11.039.

31. Allahbakhsh, A.; Bahramian, A. R., Self-assembly of graphene quantum dots into hydrogels and cryogels: Dynamic light scattering, UVVis spectroscopy and structural investigations. Journal of Molecular Liquids 2018, $265, \quad 172-180$. https://doi.org/10.1016/j.molliq.2018.05.123.

32. Esfahani, M. R.; Stretz, H. A.; Wells, M. J., Abiotic reversible self-assembly of fulvic and humic acid aggregates in low electrolytic conductivity solutions by dynamic light scattering and zeta potential investigation. Science of the Total Environment 2015, 537, 81-92. https://doi.org/10.1016/j.scitotenv.2015.08.001.

33. Braun, J.; Renggli, K.; Razumovitch, J.; Vebert, C., Dynamic light scattering in supramolecular materials chemistry. Supramolecular Chemistry: From Molecules to Nanomaterials 2012. https://doi.org/10.1002/9780470661345.smc039.

34. Palmer, N. E.; von Wandruszka, R., Dynamic light scattering measurements of particle size development in aqueous humic materials. Fresenius' Journal of Analytical Chemistry 2001, 371, (7), 951-954. https://doi.org/10.1007/s002160101037.

35. Pinheiro, J.; Mota, A.; d'Oliveira, J.; Martinho, J., Dynamic properties of humic matter by dynamic light scattering and voltammetry. Analytica Chimica Acta 1996, 329, (1-2), 15-24. https://doi.org/10.1016/0003-2670(96)00097-9.

36. Baalousha, M.; Motelica-Heino, M.; Le Coustumer, P., Conformation and size of humic substances: Effects of major cation concentration and type, pH, salinity, and residence time. Colloids and Surfaces A: Physicochemical and Engineering Aspects 2006, 272, (1-2), 48-55. https://doi.org/10.1007/s002160101037. 
37. Liu, F.; Wei, X.; Xie, R.; Wang, Y.; Li, W.; Li, Z.; Li, P.; Zong, Z., Characterization of oxygen-containing species in methanolysis products of the extraction residue from Xianfeng lignite with negative-ion electrospray ionization Fourier transform ion cyclotron resonance mass spectrometry. Energy \& Fuels 2014, 28, (9), 5596-5605. https://doi.org/10.1021/ef501414g.

38. Liu, S. S.; Zhu, Y. R.; Liu, L. Z.; He, Z. Q.; Giesy, J. P.; Bai, Y. C.; Sun, F. H.; Wu, F. C., Cation-induced coagulation of aquatic plantderived dissolved organic matter: Investigation by EEM-PARAFAC and FT-IR spectroscopy. Environmental Pollution 2018, 234, 726-734. https://doi.org/10.1016/j.envpol.2017.11.076.

39. Song, F.; Wang, X.; Li, T.; Zhang, J.; Bai, Y.; Xing, B.; Giesy, J. P.; Wu, F., Spectroscopic analyses combined with Gaussian and CoatsRedfern models to investigate the characteristics and pyrolysis kinetics of sugarcane residue-derived biochars. Journal of Cleaner Production 2019, 237, 117855. https://doi.org/10.1016/j.jclepro.2019.117855.

40. Zhao, J.; Guo, Q.; Huang, W.; Zhang, T.; Wang, J.; Zhang, Y.; Huang, L.; Tang, Y., Shape Tuning and Size Prediction of Millimeter-Scale Calcium-Alginate Capsules with Aqueous Core. Polymers 2020, 12, (3), 688. https://doi.org/10.3390/polym12030688.

41. Instruments, M., Zetasizer Nano Series User Manual-MAN0317 Issue 1.0. In Malvern Instruments Ltd., England, 2003.

42. Fei, G.; Shuai, Q. A.; Lei, X. A.; Yb, A.; Bx, C., Thermal degradation features of soil humic acid sub-fractions in pyrolytic treatment and their relation to molecular signatures. Science of The Total Environment 2020, 749. https://doi.org/10.1016/j.scitotenv.2020.142318.

43. Montoneri, E.; Boffa, V.; Quagliotto, P.; Mendichi, R.; Chierotti, M.; Roberto, G.; Medana, C., Humic acid-like matter isolated from green urban wastes. Part I: structure and surfactant properties. Bioresources 2008, 3, (1), 123-141. https://doi.org/10.1007/s00226-007-0175-0.

44. Savarino, P.; Montoneri, E.; Musso, G.; Boffa, V., Biosurfactants from urban wastes for detergent formulation: surface activity and washing performance. Journal of Surfactants and Detergents 2010, 13, (1), 59. https://doi.org/10.1007/s11743-009-1133-7.

45. Chilom, G.; Bruns, A. S.; Rice, J. A., Aggregation of humic acid in solution: Contributions of different fractions. Organic Geochemistry 2009, 40, (4), 455-460. https://doi.org/10.1016/j.orggeochem.2009.01.010.

46. Holger; Lippold; and; Uta; Gottschalch; and; Hermann; Kupsch, Joint influence of surfactants and humic matter on PAH solubility. Are mixed micelles formed? Chemosphere 2008, 70, (11), 1979-1986. https://doi.org/10.1016/j.chemosphere.2007.09.040.

47. Hattori, K., Chemical and biological studies on environmental humic acidsI. Composition of elemental and functional groups of humic acids. Soil Science and Plant Nutrition 1988. https://doi.org/10.1080/00380768.1988.10416472.

48. Dai, J. Y.; Ran, W.; Xing, B. S.; Gu, M.; Wang, L. S., Characterization of fulvic acid fractions obtained by sequential extractions with pH buffers, water, and ethanol from paddy soils. Geoderma 2006, 135, 284-295. https://doi.org/10.1016/j.geoderma.2006.01.003.

49. Qian, X.; Lee, S.; Soto, A.-m.; Chen, G., Regression model to predict the higher heating value of poultry waste from proximate analysis. Resources 2018, 7, (3), 39. https://doi.org/10.3390/resources7030039.

50. Jovanović, U. D.; Marković, M. M.; Cupać, S. B.; Tomić, Z. P., Soil humic acid aggregation by dynamic light scattering and laser Doppler electrophoresis. Journal of Plant Nutrition and Soil Science 2013, 176, (5), 674-679. https://doi.org/10.1002/jpln.201200346.

51. Klučáková, M.; Věžníková, K., Micro-organization of humic acids in aqueous solutions. Journal of Molecular Structure 2017, $1144,33-40$. https://doi.org/10.1016/j.molstruc.2017.05.012.

52. Baigorri, R.; Fuentes, M.; González-Gaitano, G.; García-Mina, J. M., Analysis of molecular aggregation in humic substances in solution. Colloids and Surfaces A: Physicochemical and Engineering Aspects 2007, 302, (1-3), 301-306. https://doi.org/10.1016/j.colsurfa.2007.02.048. 